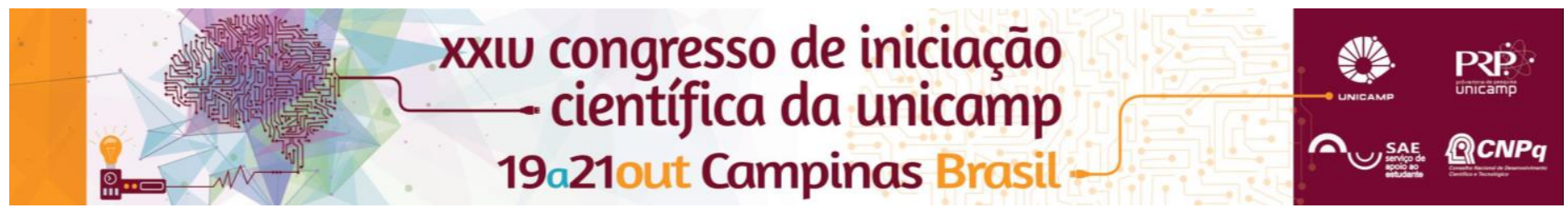

\title{
Microvascular thrombosis in sepsis and septic shock: an autopsy study
}

\author{
Vanessa M Tani*, Guilherme Rossi Assis de Mendonça, Thamires Branco da Silva, Fabio Rogerio, Erich V De \\ Paula.
}

\begin{abstract}
For years, activation of coagulation and formation of microthrombi were considered critical mechanisms of tissue damage in sepsis. However, clinical trials with anticoagulants did not show benefits in sepsis patients. In order to check the relevance of activation coagulation as a mechanism of tissue damage in sepsis, we evaluated the presence of vascular microthrombi in autopsies of 51 patients deceased by septic shock in HC-Unicamp..
\end{abstract}

Key words: sepsis, septic shock, microvascular thrombosis

\section{Introduction}

Sepsis is the main cause of death in non-coronary ICUs in Brazil, with mortality rates as high as $65 \%$ in some populations, despite improvements in the understanding of its pathogenesis. Coagulation activation is a hallmark of sepsis, as illustrated by the frequent association of sepsis and disseminated intravascular coagulation. In fact, many authors consider coagulation activation leading to microvascular thrombosis as one of the pathogenic mechanisms responsible organ damage in sepsis (Semeraro et al. , 2012). The association between microvascular thrombosis and tissue damage stems from a series of autopsy studies performed in the 1970s and 1980s, which reported very high rates of microthrombi in these patients. However, some of these studies included very few patients with sepsis, while others could not confirm these results (reviewed in Semeraro et al, 2012). These limitations were largely ignored for almost two decades, as data from animal models and other in vitro experimental studies confirmed the association between sepsis and coagulation activation. As a consequence, large clinical trials using natural anticoagulants to block coagulation activation during sepsis were conducted, all of them with negative results. Together, these data question the role of hemostatic activation in the pathogenesis of severe sepsis. More recently, the prevalence of microvascular thrombi in patients with sepsis was revisited in an elegant prospective study which analyzed kidney post-mortem biopsies of 19 patients who died due to septic shock, which did not find microvascular thrombosis as a prominent histopathological characteristic (Lerolle et al., 2010). Here, we investigated the prevalence of microvascular thrombi in a consecutive database of autopsy reports of patients who died due to sepsis or septic shock, in a University Hospital in Brazil

\section{Results and Discussion}

This retrospective study was conducted in a University Hospital in Brazil researching an autopsy database for reports of patients that died due to sepsis or septic shock, between 2008 and 2014. In total, 55 autopsy reports were identified, of which 51 were analyzed in this study. Four reports from patients younger than 12 years-old were excluded from the analysis. The study was approved by the local Institutional Review Board, and performed in accordance with the Declaration of Helsinki. In an attempt to discriminate renal and pulmonary lesion from agonal phenomena, we compared the results from these reports with those from a group of 10 controls from the same autopsy database. The inclusion criteria for the control group was death due non-infectious and non-neoplastic conditions (trauma, hypovolemic shock and acute myocardial infarction). Reports were analyzed individually by one of the investigators, which compiled all autopsy findings in lungs and kidneys, which were described in all reports. Next, a panel of three investigators categorized these findings, specifically searching for terms indicating the presence of microvascular thrombosis.Clinical and demographic data were obtained from the autopsy reports.

Table 1. Patient characteristics

\begin{tabular}{|l|c|c|}
\hline Patient characteristics & $\begin{array}{c}\text { Septic } \\
\text { shock } \\
(\mathbf{n = 5 1 )}\end{array}$ & $\begin{array}{c}\text { Control } \\
\text { subjects }(\mathbf{n}=10)\end{array}$ \\
\hline Age, median (range) & $55(16-81)$ & $43(35-63)$ \\
\hline Sex (male:female) & $32: 19$ & $3: 7$ \\
\hline Survival ${ }^{*}$, median (range) & $8(0-104)$ & $5(1-16)$ \\
\hline
\end{tabular}

* Days since admission

Table 2. Prevalence of microvascular thrombi

\begin{tabular}{|l|c|c|c|}
\hline & $\begin{array}{c}\text { Septic shock } \\
(\mathbf{n}=51)\end{array}$ & $\begin{array}{c}\text { Control } \\
\text { subjects }(\mathbf{n}=10)\end{array}$ & $\mathbf{P}$ \\
\hline Lung & $3 / 48$ & $0 / 10$ & 1.0 \\
\hline Kidney & $3 / 48$ & $0 / 10$ & 1.0 \\
\hline
\end{tabular}

Table 3. Association of microvascular thrombi with clinical characteristics

\begin{tabular}{|l|c|c|c|}
\hline & $\begin{array}{c}\text { Thrombi + } \\
(\mathbf{n = 5})\end{array}$ & $\begin{array}{c}\text { Thrombi } \\
\text { absent }(\mathbf{n}=46)\end{array}$ & $\mathbf{P}$ \\
\hline $\begin{array}{l}\text { Age, median } \\
\text { (range) }\end{array}$ & $63(38-71)$ & $51(16-81)$ & 0.12 \\
\hline $\begin{array}{l}\text { Survival*, } \\
\text { median (range) }\end{array}$ & $7(2-38)$ & $8(0-104)$ & 0.59 \\
\hline
\end{tabular}

\section{Conclusions}

In conclusion, microvascular thrombosis was not a prominent post-mortem finding in patients who died due to sepsis or septic shock in our retrospective cohort. The relevance of microvascular thrombosis in the pathogenesis of sepsis should be revisited.

Semeraro, N., Ammollo, C. T., Semeraro, F., \& Colucci, M. (2012). Sepsis, thrombosis and organ dysfunction. Thrombosis Research, 129(3), 290-5.

Lerolle $\mathrm{N}^{1}$, Nochy D, Guérot E, Bruneval P, Fagon JY, Diehl JL, Hill G..Histopathology of septic shock induced acute kidney injury: Apoptosis and leukocytic infiltration. Intensive Care Med. 2010;36:471-478. 